\title{
A ÉTICA DO ATOR NA CONSTRUÇÃO DA POIESIS
}

Raylson Silva da Conceição

Orientador (a): $\operatorname{Prof}^{\mathrm{a}} \mathrm{Dr}^{\mathrm{a}}$ Michelle Nascimento Cabral Fonseca

\section{RESUMO}

Este artigo tem como finalidade analisar a importância da ética do ator na construção da poiesis para a produção do conhecimento no fazer teatral. Sendo assim, levanto questões sobre a construção científica da poiesis, bem como o compromisso do ator com o olhar epistemológico, reflexivo e crítico do espectador. Para tanto, faz-se necessário entender as estruturas da poiesis no acontecimento teatral por meio do conceito de teatro do crítico argentino Jorge Dubatti e a ética do “artista marginal” do pintor francês Gustave Couber. O trabalho é dividido em alguns tópicos desenvolvidos da seguinte forma: POIESIS TEATRAL: Compromisso ou Liberdade? que mostra que durante a minha vida acadêmica muitas vezes foram levantas questões no curso de Licenciatura em Teatro da Universidade Federal do Maranhão - UFMA e até mesmo fora do contexto acadêmico: O teatro deve ser visto por meio de teorias? Qual a importância do conhecimento acadêmico na expectação e produção artística local? O conhecimento acadêmico deve ficar somente entre os muros da academia? As teorias teatrais são obstáculos ou contribuem para o fazer teatral?. Alguns atores viam as teorias como impedimento para a criação artística, o que por sua vez fomentava uma construção subjetiva da arte tornando qualquer ideia permissível para uma apresentação o que resultava na “qualquercoisologia” (DUBATTI, 2016). Mas, o que é arte? Para a filosofia teatral de Jorge Dubatti, arte é a construção científica, portanto, se a arte é a construção científica aos olhos da filosofia teatral, logo, a produção artística não pode ser “doxa”, mas, “provada”. Como estudar ou analisar uma criação subjetiva? Como sistematizar uma criação subjetiva? Alguns artistas produzem a sua arte apenas com a intenção de ser aceita e nuca questionada. Será por isso que recorrem à subjetividade? A fuga de uma análise epistemológica da sua arte? Segundo Aristóteles, a construção dos primeiros conhecimentos do homem ocorre por meio do olhar e da assimilação do que ver. É possível construir conhecimento por meio de uma construção artística subjetiva onde não permite o questionamento e a dialética, mas, tão somente o posicionamento 
passivo de uma contemplação de estilos onde sobrepuja o conteúdo de (in) formação?Para entendermos o teatro como acontecimento e, portanto, como construtor do conhecimento, segundo a filosofia teatral de Jorge Dubatti, é importante ressaltar a junção de três aspectos no mesmo espaço-tempo durante o fazer teatral, a saber, o “convívio”, a “poiesis” e a “expectação” (DUBATTI, (2016). Sem esta junção no mesmo espaço-tempo, segundo Dubatti, não é teatro se constituindo em outra linguagem artística como cinema, performance etc. Sendo assim, entendemos o teatro na filosofia teatral como "presença carbônica” dos corpos possibilitando o pensar sobre a ação do ator, portanto, a construção do conhecimento. Analisaremos a sistematização da poiesis proposta pela filosofia teatral, especificamente na disciplina da Poética Teatral. Esta disciplina supera a semiótica em que ver o teatro como linguagem. Para tanto, existe a distinção entre a Poética Teatral (com maiúscula), poética (com minúscula) e a Poética Comparada. Esta disciplina propõe uma análise sistemática e integral de aspectos e ângulos exigidos pelo acontecimento teatral que consequentemente nos permite entender como acontece a construção do conhecimento no espetáculo teatral. A Poética organiza o acontecimento teatral na sua totalidade "poética-convivial-espectatorial” possibilitando também analisar este acontecimento por meio da poiesis produtiva (ator), poiesis receptiva (espectador) e a zona de experiência (convívio e expectação), portanto: “[...] denomina-se Poética Teatral a partir do exame da complexidade ontológica da poiesis teatral em sua dimensão produtiva, receptiva e da zona de experiência que esta funda na pragmática do convívio e da expectação” (DUBATTI, 2016, p. 47); A contribuição do espectador na poiesis mostra outro importante aspecto levantado pelo teórico argentino é que “a poiesis é sempre provisória, já que se define pelo discurso histórico que a caracteriza: ela é, portanto, o discurso que, historicamente, construímos sobre o conjunto de componentes construtivos do ente poético”, pois, se define por discurso histórico, ou seja, esta poiesis é definida por um discurso que construímos sobre a produção do “ente poético” (DUBATTI, 2016, p. 47). Se construímos um discurso sobre aquilo que vemos em um espetáculo de teatro, implica dizer que o ator tem um compromisso com o espectador da sua obra e responsabilidade na sua criação uma vez que a sua poiesis possibilitará a produção de novos pensamentos. Com base na filosofia teatral é possível entendermos como acontece a análise, reflexão e olhar epistemológico do espectador para a construção do conhecimento uma vez que a poiesis está divida em duas categorias, a “poiesis 
implícita” e "poiesis explicita” (DUBATTI, 2016). A poiesis implícita é a construção do ente poético (ator) que ainda não foi submetida ao discurso (olhar epistemológico e crítico do espectador), enquanto que a poiesis explícita foi submetida ao discurso interpretativo e reflexivo do espectador. Portanto, a poiesis vista por meio do convívio sem recursos tecnológicos que possibilitem a visualização desta poiesis à distância, portanto, presença dos corpos, possibilita com que a poiesis implícita, ou seja, ainda não expectada, seja ilimitada, enquanto que a poiesis explicita (já apresentada ao espectador) é provisória e está permanentemente sujeita a revisão, aperfeiçoamento e polêmica (DUBATTI, 2016, p. 48). Segundo o teórico, esta poiesis é provisória e sujeita a revisão e polêmica por se tratar de um acontecimento efêmero, pois, por "seu caráter vivente, efêmero, incapturável, imprevisível e impredizível, a poiesis tetral, a nova forma do novo ente, nunca é a mesma em cada acontecimento” (DUBATTI, 2016, p. 49). Levando esta análise para o espectador e o ator, em que para o espectador só é possível a "poiesis explícita”, enquanto que a “poiesis implícita” cabe ao ator, a poiesis do ator dada à reflexão do seu público, faz dela provisória e sujeita a revisão e aperfeiçoamento, pois, o espectador também faz contribuições para a poiesis do ator que por sua vez já não é mais sua, mas, de todos por meio do convívio e da expectação com a necessidade da presença dos corpos, complementando com Grotowski: “os espectadores e os atores são ao mesmo tempo observadores e observados.” (GROTOWSKI; FLAZEN, 2010), portanto, construtores mútuos no fazer teatral. A arte não possui dono. A sua característica está em não ser contida ou domada, mas, se manifestar em várias formas, corpos ou lugares. A arte do ator não pertence a si e como uma mãe que gera um filho ao mundo, a sua arte nasce para ser expectada e consumida pelos olhos devoradores e famintos; A Produção de uma nova forma/ conhecimento mostra a forma como Dubatti coloca três tipos de poiesis, a poiesis produtiva, poiesis receptora e a poiesis convivial. A poiesis produtiva é a poiesis entendida pela ação do ator; a poiesis receptora por parte do espectador que ver o fazer teatral com olhar epistemológico para a construção do conhecimento e por ultimo a poiesis convivial manifesta na presença carbônica dos corpos, ou seja, no acontecimento da reunião. Mas ambas as poiesis são produtiva uma vez que a poiesis receptora analisa, no acontecimento teatral de forma reflexiva e epistemológica, a poiesis do ator, o que por sua vez, produz novas formas de pensar. Portanto, também é importante ver esta segunda poiesis como construtora do conhecimento que só é permitida tal construção por 
meio do convívio, pois, segundo Dubatti, as ações corporais do ator produzem "nova forma” que por sua vez produz "matéria diversas" e que nunca se repete em cada acontecimento teatral (DUBATTI, 2016). Por isso é importante pensarmos na importância da ciência na construção da poiesis, visto que, ela estimula o pensar e, portanto, a construção do conhecimento no acontecimento teatral. Sendo assim, é necessário a ciência na construção desta poiesis e na expectação desta "nova forma" do "ente poético", onde o ator instaura "um campo de distinção entre a gramática da realidade cotidiana no cronotopo cotidiano e a nova gramática do ente poético” (DUBATTI, 2016, p. 49). A riqueza de conteúdos dialogadas em uma poiesis visto por meio da filosofia e construída por meio da ciência, possibilita a construção de novos conhecimentos no acontecimento teatral atrás da percepção de um olhar disciplinado capaz de contemplar a "gramática do ente poético” (DUBATTI, 2016). Sendo assim, Barbara Botter nos apresenta esta necessidade, observada por Platão, de desenvolvimento deste órgão que nos possibilita aprender. Não basta olhar, aprendemos por meio da compreensão do que vemos, mas que é necessário ferramentas para direcionar o olhar. Isto é o que Platão chama de faculdade da alma, a capacidade de olhar. Voltar o corpo para olhar um espetáculo teatral é voltar um olhar que possibilite a reflexão e contemplação do que está vendo e a isto o filósofo grego chama de "Ser", ou seja, o bem maior do homem; O Ator Filosófico: Arte e Ciência mostra a construção científica do teatro, em que, segundo Dubatti, é a construção científica também sobre o ator que o define como tal. Para a filosofia teatral, o ator é o responsável pelo acontecimento teatral por meio das suas ações corporais gerando uma nova forma por meio da poiesis. Dubatti defende que sem a poiesis não existe a expectação teatral, uma vez que o ator não pode se ausentar do acontecimento teatral. Jerzy Grotowski e Peter Brook são exemplos deste tipo de teatro onde evidenciam a importância da relação entre o ator e o espectador. Portanto, os dois viventes no teatro, o espectador e o ator, produzem poiesis no seu convívio. Uma é a poiesis produtiva (ator) e a outra a poiesis receptiva (espectador) que se relacionam na construção do conhecimento, mas que sem a poiesis do ator nenhum acontecimento teatral é possível, ao contrário da poiesis do espectador que se renova a cada espetáculo, tanto pela efemeridade do espetáculo quanto pela “circulação” do espectador (DUBATTI, 2016). Temos mais do que evidencia para entendermos o quão importante o ator é para a construção do convívio, da reunião e até mesmo do conhecimento no fazer teatral. A sua poiesis é necessária para a construção do 
conhecimento do seu público fundamentando o que Tescarolo (2012) disse sobre a maiêutica, em que o conhecimento está latente no ser humano de forma a esperar apenas um estimulo para dar a luz ao conhecimento. A poiesis do ator possibilita a (a)parição do conhecimento. Sendo assim, o ator tem um comprometimento com a sua poiesis uma vez que ele é diretamente responsável pela construção do pensamento do espectador. $\mathrm{O}$ ator não deve fazer a sua arte de qualquer forma. A sua arte não deve ser apenas aceita. A sua arte necessita de bases teóricas para a construção da sua poiesis. Caso contrário, este ator seria um ator marginal que está a margem da construção cientifica do teatro e até mesmo das necessidades do seu público; Artista Marginal: o teatro é do ator ou o teatro é de todos? em que para Pompeyo Audivert, a técnica poética é um lugar de multiplicação onde o ator é a sua maior revelação nos proporcionando uma mudança de visão e possibilitando um aprofundamento da visão crítica sobre o mundo. Portanto, entende-se que o ator é um filósofo performativo no palco, além disto, mediador entre o seu publico e o conhecimento (DUBATTI, 2016). O ator como o principal agente responsável de mudança, multiplicando a realidade em múltiplas possibilidades de "reais", possui a responsabilidade diante da construção artística, pois, por ser o centro da revelação, tem a finalidade de levar o seu espectador não somente a outro mundo (ficção), mas também a um aprofundamento no pensar. $\mathrm{O}$ ator tem uma responsabilidade muito grande com a construção da sua arte. Nesta perspectiva, levanto algumas questões sobre estas construções no contexto artístico atual onde as produções artísticas na sua maioria estão voltadas para satisfazer necessidades de editais que fomentam a produção artística no Brasil. Sendo assim, a construção do conhecimento por meio do fazer teatral como acontecimento, tem sido comprometida por esta necessidade? O ator tem se comprometido consigo, com editais ou com a formação intelectual do espectador? Para que tem servido o teatro? Ou melhor, para quem tem servido o teatro? Jorge Coli nos apresenta o “artista marginal”, um artista que não está preocupado com o que vão pensar da sua arte. Descompromissado com o mundo e com as pessoas, este artista faz da sua arte o que deseja sem se importar com os seus espectadores. Jorge Coli toma esta ideia de artista marginal do pintor francês Gustave Coubert, pioneiro no estilo realista francês que retratava a vida camponesa da sua época. Coubert se refere em suas obras do "novo artista” que tem uma "relação intrincada entre aquilo que é subjetivo e aquilo que é coletivo; entre o que é biografia individual e o que é pintura propriamente dita.” (COLI, 2010, p. 139). O seu artista 
marginal busca romper com valores de um universo que influenciavam na criação das suas obras.Coubert fala de um artista que conhece as posições éticas e políticas, e que escolhe seguir a sua própria convicção de forma a criar a sua própria ética.O próprio Coubert, por meio de uma carta aos seus discípulos em Paris no dia 25 de dezembro de 1861, incentivava os artistas a serem mestres de si mesmos alegando que ele próprio não tinha alunos e, portanto, não ensinaria a sua arte. O“artista marginal” é o artista criador da sua própria obra com base na sua própria ética. Um artista que está à margem dos estilos artísticos existentes dentro e fora da sua época em busca da construção do seu próprio estilo, mas, para que isso fosse possível, este artista teve que conhecer as estruturas às quais ele romperia e escolheria estar à margem. Em uma concepção de autenticidade, este seria a realização do artista ideal para Jerzy Grotowski, um artista capaz de romper com as releituras para a construção da sua obra de forma a construir uma arte autêntica. O artista margina é um artista descompromissado com o mundo, como citado por Coli, portanto, descompromissado com a formação do homem e do mundo. Um artista que está à margem da construção do conhecimento no fazer teatral.

Palavras Chave: Ética; Poiesis; Ciência; Teatro; Conhecimento. 